\title{
Healthcare students' perceptions of their learning experiences: a repeat regional survey.
}

\begin{abstract}
$\underline{\text { ABSTRACT }}$
Background: Student experience is an international concern and recent research has focused on initiatives to improve students' learning experiences and ultimately reduce attrition levels. Objective: To determine similarities and differences between students' perceptions of their learning experiences between 2011 and 2015 in relation to campus-based learning, placementbased learning and personal circumstances.

Design: A repeat online survey in 2011 and 2015; using a questionnaire developed from thematic analysis of narrative interviews with a subsample of the target population.

Settings: Nine universities in the North West of England.

Participants: A total of 1080 students completed the survey in 2011 and 1983 students in 2015

from a target population of all students studying on commissioned pre-registration healthcare education programmes.

Methods: An online survey was made available to all undergraduate students studying on Health Education funded programmes within the region and survey respondents were invited to give demographic information and rate their agreement to statements on four-point Likert-type responses.

Results: Responses to a repeat survey of healthcare studying in the North West of England in 2015 were strikingly similar overall to those of an origianl 2011 survey. Although the students were positive overall about their experiences, a number were dissatisfied with some aspects of their experiences - particularly in relation to initial support on campus and whilst studying on placement. Four years on from the original survey, despite a considerable investment in improving students' experiences across the region, there appears to be little change in students' perceptions of their learning experiences

Conclusion: In the short-term monitoring of student experience needs to be continued; and links to attrition (potential or actual) noted and acted upon. However, given that attrition from these courses has been a long-term problem and the complexity of its resolution a recurrent finding in the literature; new ways of framing and resolving the problem need to be considered. Key words: Student experience, student attrition, repeat survey, healthcare education
\end{abstract}




\section{INTRODUCTION}

In 2012 Hamshire et al. (2012) reported on a sequential explanatory study of healthcare students experiences in the North West of England, with respect to their expectations and perceptions of their programmes. The survey provided a baseline measure of these experiences with the intention that it might help in the development of interventions to improve students' experiences and hence potentially reduce attrition. Subsequently a repeat survey was carried out four years later in 2015 .

As previously reported (Hamshire et al., 2011, 2013) student success and retention are complex phenomena, related to a number of factors such as the education and social development of individual students prior to enrolling; the social and academic engagement between the student and the institution; job certainty, national events and the commitment of the student to the institution (Hamshire et al., 2011; Urwin et al., 2010). However, these broad categories make it difficult to ascertain the exact impact of such factors for individual students and although there is a considerable body of research on students' experiences and retention, understanding why similar circumstances can be bearable for one student, but not another is difficult. Understanding the complexity of causative factors that impact on an individual student's learning experiences and thus engagement can therefore be challenging (Currie et al., 2014); as can be predicting student success (Jones-Schenk and Harper, 2014).

Individual experiences influenced by personal factors, academic factors and outside influences all combine to create an individual set of circumstances that can either contribute to a negative experience or assist student success (Cameron et al., 2010; Jeffreys, 2012). Students continue to report a range of personal factors (for example struggle with study, finances, family circumstances) as impacting negatively on their experiences (Knight et al., 2012).

Health Profession education programmes are considered to be challenging and timeintensive, and for some students they can also be both emotionally and academically stressful (Banks et al., 2012; Barkley, 2011). Significant expectations are placed on students (Emanuel and Pryce-Miller, 2013) as they have to master detailed anatomical and pathological curricula at the same time as completing a minimum number of placement hours specified by their accrediting professional body. Ambiguous or unrealistic expectations can contribute to attrition (Cameron et al., 2010; O'Donnell, 2011; Hamshire et al., 2013) and dissatisfaction with clinical placement learning can accelerate students' decisions to leave; a supportive relationship with mentors whilst undertaking clinical placements is essential (Crombie et al., 2013; Hamshire et al., 2011).

Personal commitment and good support networks are essential elements of positive student experiences and for retention (Cameron et al., 2011; Braine and Parnell, 2011); peer support is particularly identified as influential (Gerrard and Billington, 2014; Crombie et al., 2013; Fontaine, 2014) together with personal emotional resilience (Beauvais et al., 2014; JonesSchenk and Harper, 2014; Williamson et al., 2013; Thomas et al., 2012).

Strategies that aim to improve healthcare students' experiences need to consider the student lifecycle from recruitment to graduation, to set reasonable student expectations and ensure that a career within healthcare is both desired and valued (Fontaine, 2014).

The knowledge base outlined above has been used in a number of interventions over recent years which aim to improve student experience and reduce attrition. In the North West of 
England (the area in which this repeat regional survey was undertaken) a number of initiatives funded by both individual universities and Health Education North West (HENW) have been undertaken between 2011 and 2015, with a number relating to induction to the university setting and ongoing support; and enhancement of placement learning. Therefore, it would be hoped that students' reports of their campus based learning and placement learning, if not of their personal circumstances (components identified as being of importance in relation to student experience and potential attrition (Hamshire et al., 2012)) would have improved during this period.

\section{METHODS}

The original online survey instrument was developed from the thematic analysis of narrative interviews with twenty-four students, which were conducted as phase one of the 2011 study (Hamshire et al., 2012). The same survey was used in 2015 with some additional demographic questions. This survey consisted of four sections; demographic data, campus-based learning, placement-based learning and personal circumstances. The data reported in this paper relates only to the closed questions asked (a total of 32 questions). These closed questions, with the exception of those relating to demographic data, were constructed from direct quotes from the twenty-four narrative interviews (see above). Students were asked to respond to these quotes in terms of whether they strongly agreed, agreed, disagreed or strongly disagreed with them. Responses were collated for reporting purposes in terms of agreement or disagreement. The 2015 results were compared against "expected levels" from the 2011 results and a Chi-Square Test applied to identify significantly different responses $(\mathrm{p}<0.01$ and $\mathrm{p}<0.05)$.

As reported in Hamshire et al. (2012) - which reported on the original 2011 survey - the sampling frame for the survey consisted of all students studying on NHS North West commissioned programmes, at participating institutions at the time of the study (in both 2011 and 2015). Thus a range of different students were included in the sample pertaining to those on undergraduate qualifying courses in: nursing, midwifery and a range of allied health professions.

For both surveys, ethics approval was obtained from the Manchester Metropolitan University Research Ethics Committee. The paperwork relating to the approval was made available to the Deans at all of the participating institutions who reviewed this to ensure that it was in-line with their own processes. The web-link to the survey was subsequently disseminated to all undergraduate students studying on NHS North West of England commissioned programmes at their institutions in both May 2011 and May 2015. In both years a reminder was sent after two weeks and both surveys were closed eight weeks after the start date. Students were directed towards a students' information sheet on the project website. Involvement in the project was voluntary and students had a period of six weeks to consider if they wanted to complete the survey.

\section{FINDINGS}

In 2011, 1,080 students responded to the survey from across the nine universities within the North West region used in the sampling frame. In 2015, 1,983 students responded from the same nine universities. Basic demographic data were collected for both surveys which 
demonstrates that the make up of the sample changed slightly in terms of gender and age (see Table 1).

Further data were collected in 2015 , in relation to the professional programme the students were studying on. These responses indicate which professional programmes were potentially slightly under or over represented when compared to workforce planning targets (see Table 2).

In relation to campus based learning (see Table 3) students' perceptions of the availability of resources seem to have improved from 2011 to 2015, as evidenced by the responses related to:

- There are never enough learning resources, e.g. library books or computers.

- The online resources are really good.

- The PowerPoint slides are really dull.

However, whilst there was a reduction in those agreeing that there are insufficient learning resources (from $46 \%$ to $38 \%$ ) over a third of students still believe that these resources were deficient. Similarly, over two-thirds of students still believe that lectures using PowerPoint slides were really dull. Slightly more students in the 2015 survey considered that the online resources that were developed to support on-site teaching were really good (90\%); however this is from a fairly high baseline of $81 \%$ in the 2011 survey.

Changes in relation to responses for these three items of the survey were the only ones for which there was a significant difference from 2011 to 2015. Similar proportions of students still reported on negative aspects of campus based learning in terms of:

- The academic workload was a bit of a shock at first.

- The feedback I get on assessment has not been helpful.

Thus, two-thirds of students still report feeling shocked by the required workload and students' perceptions of the feedback on their assessments being unhelpful remains at about onethird of students $(33 \%)$.

In terms of positive aspects of campus based learning the majority of students also reported that:

- On the whole it's a really positive experience for me.

- The academic staff are really helpful, if you are struggling they will listen and try to help.

- My personal tutor has been fantastic, really supportive.

- I really like the small group sessions.

Thus, only a minority of students (14\% in 2011, and 13\% in 2015) did not regard their campus-based learning as 'really positive'. Personal tutors and other academic staff were still seen to be helpful and supportive (77\% in 2011 and 80\% in 2015 of students agreeing that their personal tutor had been really supportive; and $88 \%$ of students in both surveys reporting academic staff being really helpful). In contrast to the negative perceptions of lectures represented by comments on PowerPoint slides; students reported really liking small group sessions, (82\% in 2011 and $85 \%$ in 2015).

In relation to placement learning (see Table 4) more respondents perceived that students were being used as an extra pair of hands (41\% agreeing with the statement in $2011,52 \%$ in 2015). Additionally, fewer students reported finding their 'visiting lecturer' helpful to placement learning (55\% in 2011, 47\% in 2015). Changes in relation to responses for these two items of the survey were the only ones for which there was a significant difference from 2011 to 2015. There were no significant changes in student reports in terms of negative aspects of placement based learning that:

- Placement allocation is a problem, there seems to be no consideration of where you live. 
- Travelling to and from placement was hard work because it meant long days.

- Money is tight so paying for placement travel is a struggle.

- Mentors don't have time to teach students even though they are expected to.

- You feel like you are not really respected on placement.

Thus, over three-quarters of students still found paying for placement travel a struggle (79\% in both years); with just under two-thirds considering travel was hard work as it contributed to a long working day (61\% in both years). Relatively less students reported problems of placement allocation (42\% in 2011 and 44\% in 2015), however, this is still close to half of all students. There was still a perception that mentors did not have sufficient time to teach students (49\% in 2011 and 54\% in 2015) additionally over a quarter of all students reported not really being respected on placement (28\% in 2011 and $29 \%$ in 2015).

Despite the negative views expressed above the majority of students also reported that there were positive aspects of placement based learning - with no significant changes over the years:

- I have enjoyed every single placement, they have been fantastic.

- The amount of thought, care and consideration that has gone into looking after students was impressive.

- It makes such a difference when you have a supportive mentor to guide your learning

- As long as I did the hours my mentor let me start and finish when it fitted in with travelling.

Thus, just over a third of respondents considered that they had not enjoyed every single placement (36\% in both years) with the vast majority ( $99 \%$ in both years) noting that a supportive mentor makes a difference. Nearly two-thirds of students $(63 \%$ in 2011 and 60\% in 2015) were impressed by the amount of thought, care and consideration that went into looking after students and in terms of travel, some flexibility of starting and finishing seemed to be appreciated (51\% of students in both years agreeing mentors allowing this flexibility.

In relation to personal circumstances (see Table 5) there were no significant differences in the responses to any of the questions across the two surveys. In both 2011 and 2015 the vast majority of students (96\% in 2011 and $97 \%$ in 2015) reported that:

- I carry on because I just keep thinking about the end goal and where it is going to get me.

This response, highlighted the importance to these students of an eventual career as a healthcare professional. However, respondents remained concerned about the amount of debt they were accumulating (56\% in 2011 and 54\% in 2015) and the on-going demands of the programme as a whole; (41\% in 2011 and 42\% in 2015) agreeing that they were quite unprepared for the amount of work they had to do.

Over three-quarters of students also reported in terms of positive aspects of their personal circumstances

- I have had a lot of support from my family (87\% in 2011 and $85 \%$ in 2015).

- The friendships I have made have helped me to continue on the course ( $86 \%$ in 2011 and $88 \%$ in 2015).

These responses emphasise the importance of support from family and friends required for students to continue on their programme.

An additional question at the end of each survey also asked if students had ever considered leaving their current programme. There was no significant difference in the response to this question over the two surveys with nearly a half reporting that they had considered leaving the programme (47\% in 2011 and $42 \%$ in 2015) 


\section{DISCUSSION}

The results of the repeat, regional survey of healthcare students studying in the North West of England in 2015 are strikingly similar overall to the 2011 survey (Hamshire et al., 2012). Although the students were positive overall a significant number remain dissatisfied with some aspects of their experiences, particularly in relation to initial support on campus and whilst studying on placement. Four years on, despite a considerable investment in improving students' experiences across the region there appears to be little change in students' perceptions of their learning experiences.

However, as highlighted in the literature (see introduction) the reasons for this lack of significant change in perceptions are likely to be complex, with a combination of personal concerns and challenges impacting upon student's individual perceptions of their learning experiences.

Similar findings relating to attrition have been reported over time; with the complexity and interplay of multiple variables being highlighted as a cause of "strategic challenges in managing nurse attrition" in a review of 'half a century of research' (Merkley, 2016, p.74). Jinks et al. $(2014, p, 646)$ have noted "it is perhaps salutary that many of the recruitment and retention issues facing the nursing profession today are not new as many are similar to those reported in the 1950s and 1960s".

Moreover, commissioners and providers of health education are challenged to implement inconclusive and often contradictory evidence and priorities (Wray et al., 2012). Constraints such as resources and political policy are frequently in flux and traditional linear problem-solving is ineffective when used to resolve such problems (Harris et al., 2009). There are a number of methodological difficulties in recognising how multiple factors compound and influence each other over time to lead to either retention or attrition; as such, student attrition meets many of the criteria of a 'wicked problem' The resolution of 'wicked problems' requires flexible inclusive approaches and reframing questions about the issue may be required to enable us to see how sector wide partnerships and policy could help enhance understanding (Harris et al., 2009). Such reframing will be a long-term goal, but commissioners and providers of health education should still continue to use the existing evidence-base to develop appropriate interventions.

Nevertheless whilst no single intervention will improve the experiences of a diverse student population, the findings of this study suggest that a review of both campus-based and placement-based support could invoke positive changes. Good support is essential to ensure success and progression (Ooms et al., 2013) and students appreciate it when lecturers approach them to offer help and support (Cameron et al., 2011). Students who report higher perceived faculty support are more likely to continue and be successful academically (Shelton, 2012).

\subsection{Campus-based support}

Our findings demonstrate that whilst students' perceptions of campus-based learning have improved overall since 2011, most notably in terms of learning resources and lectures; a majority were still 'shocked' by the academic workload at first; and 41\% in 2011 and $42 \%$ in 2015 reported feeling unprepared for the amount of work they had to do. Students' individual perceptions and expectations are influenced by both their previous educational experiences and the information they have acquired about their university programme from both websites and professional literature (Hamshire et al., 2013). As previously noted (Hamshire et al., 2013; 
Hughes, 2013; Cameron et al., 2010) some students can be unprepared for the academic content of their programme and feel out of their depth, particularly in science-related subjects and numeracy.

Edwards and Faulkner (2013), Hughes (2013), Knight et al. (2012) and McIntyre (2011) have suggested offering pre-entry course preparation and facilitating realistic goal setting to foster students' desire to achieve academically. In addition, O’Donnell (2011) advises that institutions need to provide accurate pre-entry information to potential students in relation to the structure, content and study requirements of a programme and Wilson et al. (2011) that interventions that are designed to increase retention and student success should ideally begin at the pre-entry stage. However, it is also noted that recruitment initiatives are rarely routinely evaluated or subsequently inked to student attrition, therefore review and evaluation of recruitment and selection to ensure that the most appropriate candidates are selected could be beneficial (Jones-Schenk and Harper 2014; Hughes 2013; Rodgers et al., 2013).

Students in both 2011 and 2015 clearly valued support from academic staff and their personal tutors as well as small group teaching sessions. Enculturation into a healthcare profession and institutional environment is a learning process and students can experience stress as they adapt, particularly if their expectations remain unmet (Jeffreys, 2012). Therefore institutions need to be aware of this and create supportive environments that facilitate a sense of belonging (Williamson et al., 2013). Unmet expectations and a perceived lack of support can have a negative effect on students' satisfaction and decision to continue on a programme (McKendry et al., 2014; Wright and Wray, 2012: Hamshire et al., 2013; O’Donnell, 2011) and students continue to give 'wrong career choice' as a reason for voluntary attrition (Hughes, 2013). As suggested by Mooring (2016) if we are to increase retention then students must be met at their level of need.

\subsection{Placement-based learning}

The majority of students in both 2011 and 2015 enjoyed their placement experiences overall; the only significant changes in students' perceptions of the placement experiences were an increase in students perceiving that they were used as 'an extra pair of hands' and a decrease in those finding their visiting lecturer helpful. Clinical placements are a vital and significant element of every healthcare programme, providing an environment in which students can make the link between theory and practice in preparation for future roles (Frazer et al., 2014; Gidman et al., 2011).

Whilst studying on clinical placement, students are unable to easily access university support services (Banks et al., 2011) and it is therefore essential that appropriate mechanisms of maintaining a support network are in place throughout clinical placement study. As noted by $99 \%$ of students in this study, good working relationship with a supportive mentor is central to a positive placement experience (Gidman et al., 2011) and the mentor's human qualities and pedagogical skills are pivotal for this (Jokelainen et al., 2011). Identification with mentors and 'being a nurse' is a strong predictor of nurse retention (McKendry et al., 2014; Wilson et al., 2011) and expectations are invariably challenged when students undertake their first placement (Barkley, 2011).

\subsection{Personal experiences and expectations}

There were no significant differences in students' perceptions of their personal circumstances across the two studies. Students continued to report concerns about their financial circumstances and it has been repeatedly noted that healthcare students experience financial 
difficulties (Hamshire et al., 2011). It is particularly noted that support from family and friends remains important for over three-quarters of students. Support from family, friends and peers can be pivotal in facilitating student continuation when students consider leaving (Hamshire et al., 2013; Knight et al., 2012). In addition Williamson et al. (2013) noted that friendship groups are instrumental in retaining nursing students and suggested that institutions need to work to facilitate the formation of peer support groups.

\section{CONCLUSIONS}

Recruitment and retention on nursing and other health-related education courses has been and will remain, an important aspect of the outcome measure for education aimed at this group of students. It is politically and practically a problem that has troubled governments and commissioners and providers of both health and education services.

In the short-term student experience needs to be monitored and links to attrition (potential or actual) noted and acted upon. However, given that attrition from these courses has been a long-term problem and the complexity of its resolution a recurrent finding in the literature; a new way of framing and taming the problem needs to be considered in the longer term. Further research to explore the potential for the application of the concept of 'wicked problems' to advance understanding of the complexity of student attrition is worthy of consideration.

\section{REFERENCES}

Banks, P., Kane, H., Rae, C., Atkinson, J., 2012, 'Support for nursing and midwifery students: A special case?' Nurse Education Today 32(3), 309-314

Barkley, A., 2011, 'Ideals, expectations and reality: Challenges for student midwives.' British Journal of Midwifery 19(4), 260-264

Beauvais, A.M., Stewart, J.G., DeNisco, S., Beauvais, J.E., 2014, 'Factors related to academic success among nursing students: A descriptive correlational research study.' Nurse Education Today 34(6), 918-923

Braine, M.E., Parnell, P., 2011, 'Exploring student's perceptions and experience of personal tutors.' Nurse Education Today

Cameron, J., Roxburgh, M., Taylor, J., Lauder, W., 2010, 'Why students leave in the UK: an integrative review of the international research literature.' Journal of Clinical Nursing 20(7-8), 1086-1096

Cameron, J., Roxburgh, M., Taylor, J., Lauder, W., 2011, 'An integrative literature review of student retention in programmes of nursing and midwifery education: why do students stay?' Journal of Clinical Nursing 20(9-10), 1372-1382

Crombie, A., Brindley, J., Harris, D., Marks-Maran, D., Morris Thompson, T., 2013, 'Factors that enhance rates of completion: What makes students stay?' Nurse Education Today $33(11), 1282-1287$

Currie, K., McCallum, J., Murray, J., Scott, J., Strachan, E., Yates, L., Wright, M., 2014, 'Developing a national computerised absence monitoring and management system to 
reduce nursing student attrition: Evaluation of staff and student perspectives.' Nurse Education Today 34(5), 738-743

Edwards, A., Faulkner, S., 2013, 'Pre-course preparation in a virtual world: An evaluation.' British Journal of Midwifery 21(11), 814-817

Emanuel, V., Pryce-Miller, M., 2013, 'Creating supportive environments for students.' Nursing Times 109(37), 18-20

Fontaine, K., 2014, 'Effects of a retention intervention program for associate degree nursing students.' Nursing Education Perspectives 35(2), 94-99

Frazer, K., Connolly, M., Naughton, C., Kow, V., 2014, 'Identifying clinical learning needs using structured group feedback: First year evaluation of pre-registration nursing and midwifery degree programmes.' Nurse Education Today 34(7), 1104-1108

Gerrard, S., Billington, J., 2014, 'The perceived benefits of belonging to an extra curricular group within a pre-registration nursing course.' Nurse Education in Practice 14(3), 253-258

Gidman, J., McIntosh, A., Melling, K., Smith, D., 2011, 'Student perceptions of support in practice.' Nurse Education in Practice 11(6), 351-355

Hamshire, C., Willgoss, T.G., Wibberley, C., 2011, "'The placement was probably the tipping point'. The narratives of recently discontinued students.' Nurse Education in Practice 12(4), 182-186

Hamshire, C., Willgoss, T.G., Wibberley, C., 2012, 'Should I stay or should I go? A study exploring why healthcare students consider leaving their programme.' Nurse Education Today 33(8), 889-895

Hamshire, C., Willgoss, T.G., Wibberley, C., 2013, 'What are reasonable expectations? Healthcare student perceptions of their programmes in the North West of England.' Nurse Education Today 33(2), 173-179

Harris, M., Vanderboom, C. and Hughes, R., 2009, 'Nursing-sensitive safety and quality outcomes: the taming of a wicked problem?' Applied Nursing Research 22, 146-151

Jinks, A.M., Richardson, K., Jones, C. and Kirton, J.A., 2014, 'Issues concerning recruitment, retention and attrition of student nurses in the 1950/60s: A comparative study' Nurse Education in Practice 14, 641-647

Hughes, H.A., 2013, 'Factors influencing attrition rates in midwifery students.' Nursing Standard 27(26), 42-48

Jeffreys, M.R., 2012, Nursing student retention. Understanding the process and making a difference, $2^{\text {nd }}$ ed. New York: Springer Publishing Company.

Jokelainen, M., Jamookeeah, D., Tossavainen, K., Turunen, H., 2011, 'Building organizational capacity for effective mentorship of pre-registration nursing students during placement learning: Finnish and British mentors' conceptions.' International Journal of Nursing Practice 17(5), 509-517

Jones-Schenk, J., Harper, M.G., 2014, 'Emotional intelligence: An admission criterion alternative to cumulative grade point averages for prelicensure students.' Nurse Education Today 34(3), 413-420

Knight, J., Corbett, A., Smith, C., Watkins, B., Hardy, R., Jones, G. , 2012, “"What made me stay?" A review of the reasons student nurses enrolled in a Bachelor of Nursing programme completed their studies: A descriptive phenomenological study.' Nurse Education Today 32(8), e62-e65

Merkley, B. R., 2016, 'Student nurse attrition: A half century of research,' Journal of Nursing Education and Practice 6(3), 71-75 
McIntyre, H.R., 2011, 'Midwifery taster course for prospective midwifery students.' British Journal of Midwifery 19(1), 57-60

McKendry, S., Wright, M., Stevenson, K., 2014, 'Why here and why stay? Students' voices on the retention strategies of a widening participation university.' Nurse Education Today 34(5), 872-877

O'Donnell, H., 2011, 'Expectations and voluntary attrition in nursing students.' Nurse Education in Practice 11(1), 54-63

Ooms, A., Fergy, S., Marks-Maran, D., Burke, L., Sheehy, K., 2013, 'Providing learning support to nursing students: A study of two universities.' Nurse Education in Practice 13(2), 89-95

Rodgers, S., Stenhouse, R., McCreaddie, M., Small, P., 2013, 'Recruitment, selection and retention of nursing and midwifery students in Scottish Universities.' Nurse Education Today 33(11), 1301-1310

Shelton, E.N., 2012, 'A model of nursing student retention.' International Journal of Nursing Education Scholarship 9(1), 1-16

Thomas, J., Jack, B.A., Jinks, A.M., 2012, 'Resilience to care: A systematic review and metasynthesis of the qualitative literature concerning the experiences of student nurses in adult hospital settings in the UK.' Nurse Education Today 32(6), 657-664

Urwin, S., Stanley, R., Jones, M., Gallagher, A., Wainwright, P. and Perkins, A., 2010, 'Understanding student nurse attrition: learning from the literature.' Nurse Education Today 30(2), 202-207

Williamson, G.R., Health, V., Proctor-Childs, T., 2013, 'Vocation, friendship and resilience: a study exploring nursing student and staff views on retention and attrition.' The Open Nursing Journal 7, October,, 149-156

Wilson, A., Chur-Hansen, A., Marshall, A., Air, T., 2011, 'Should nursing-related work experience be a prerequisite for acceptance into a nursing programme? A study of students' reasons for withdrawing from undergraduate nursing at an Australian university.' Nurse Education Today 31(5), 456-460

Wray, J., Barrett, D., Aspland, J., Gardiner E., 2012, 'Staying the course: Factors influencing pre-registration nursing student progression into Year 2-A retrospective cohort study.' International Journal of Nursing Studies 49(11), 1432-1442

Wright, J., Wray, J., 2012, 'Exploring the experiences and expectations of year 1 children's nursing students.' Nursing Children and Young People 24(4), 24-28 